\title{
PERCUTANEOUS LEFT VENTRICULAR PUNCTURE WITH CATHETERIZATION OF THE AORTA
}

\author{
BY \\ H. A. FLEMING, E. W. HANCOCK,* B. B. MILSTEIN, AND D. N. ROSS \\ From Brompton Hospital and Guy's Hospital, London
}

(RECEIVED FOR PUBLICATION JANUARY 21, 1958)

The technique of percutaneous puncture of the left ventricle for the assessment of patients with aortic stenosis was described by Brock, Milstein, and Ross (1956) and the results in the first 28 cases were analysed by Fleming and Gibson (1957). This procedure has now been carried out in 115 patients at these two hospitals and the technique has been extended to include catheterization of the aorta via the left ventricular needle. This paper describes our experience with catheterization of the aorta by this method in the first 36 attempts.

It is desirable to catheterize the aorta for two reasons. First, pressure tracings recorded continuously during the withdrawal of the catheter tip from the aorta to the left ventricle may reveal subvalvar stenosis undetectable by any other method short of surgical exploration (Brock and Fleming, 1956). This is an important consideration in all patients with congenital aortic stenosis and in patients with severe left ventricular hypertrophy due to aortic valve stenosis or to hypertension (Brock, 1957b). Second, the systolic pressure gradient across the aortic valve is calculated more accurately from the aortic pressure pulse than from a peripheral arterial pulse. Although the difference between the central and peripheral pulse contours is usually small in aortic stenosis (Wright, Toscano-Barboza, and Brandenburg, 1956) the variability of this has not yet been fully explored.

\section{METHOD}

The basic technique for percutaneous left ventricular puncture remains as already described (Brock and others, 1956). The use of the catheter requires a larger bore needle than previously used for left ventricular puncture alone in which a needle of 18 gauge (external diameter $1.1 \mathrm{~mm}$.) is used. A 16-gauge needle (external diameter $1.5 \mathrm{~mm}$.) allows easy passage of nylon (Portex No. 2) or polythene tubing of $0.74 \mathrm{~mm}$. internal diameter and $0.94 \mathrm{~mm}$. external

\footnotetext{
* Research Fellow, American Heart Association.
}

diameter and has been found adequate for pressure recordings of excellent quality (Figs. 2-7). The needle, catheter, and adaptor assembly are illustrated in Fig. 1. A sidearm on the needle and a rubber seal around the catheter at its entrance into the needle hub can be used to allow a continuous slow irrigation of heparinized saline between the needle and the catheter. This prevents the development of stickiness, which can sometimes impede the free movement of the catheter and also guards against clots or bubble being sucked into the ventricle in diastole. This refinement has not been used in the present series. A very slow drip of heparinized saline is also used in the catheter to prevent the reflux and clotting of blood.

The junction of the shaft of the needle with the butt may need some attention to permit the free movement of the catheter. A coiled catheter is undesirable and should be straightened out by hanging overnight with a weight on the end. Such straightened catheters enter the aorta readily if the needle is properly directed along the outflow tract of the left ventricle and are also less apt to kink or snare off when withdrawn over a sharp needle tip. Nylon is rather more liable to kink and polythene more liable to snare, but the tendency in each case is slight. If there is any suggestion of snaring no force must be used and the catheter and needle must be withdrawn together from the chest and the puncture repeated. This has seldom been necessary.

\section{RESULTS}

The results of the first 36 attempts are summarized in Table I. The catheter entered the aorta in 28 cases $(78 \%)$, usually immediately and without ventricular irritability. In one case of suspected valvar and subvalvar stenosis (Case 26) only the subvalvar chamber could be entered. The level of systolic pressure recorded from the needle in the femoral artery confirmed the presence of both valvar and subvalvar stenosis. In two cases of pure valvar stenosis (Cases 29 and 34) the aorta could not be entered and later at necropsy the valve orifice was found to be tiny and situated peripherally in a great, craggy mass of calcium. 
TABLE I

DETAILS OF CASES INVESTIGATED (AGE RANGE FROM 5 TO 63 YEARS)

\begin{tabular}{|c|c|c|c|c|c|c|}
\hline $\begin{array}{l}\text { Case } \\
\text { No. }\end{array}$ & atient & Age & Sex & Diagnosis & $\underset{\text { Entered }}{\text { Aorta }}$ & $\begin{array}{l}\text { Standard } \\
\text { of Trace }\end{array}$ \\
\hline $\begin{array}{r}1 \\
2 \\
3 \\
4 \\
5 \\
6 \\
7 \\
8 \\
9 \\
10 \\
11 \\
12 \\
13\end{array}$ & $\begin{array}{l}\text { M.B. } \\
\text { A.B. } \\
\text { D.H. } \\
\text { C.F. } \\
\text { W.M. } \\
\text { B.W. } \\
\text { J.C. } \\
\text { M.S. } \\
\text { K.S. } \\
\text { J.T. } \\
\text { C..N. } \\
\text { A.A. }\end{array}$ & $\begin{array}{l}34 \\
15 \\
50 \\
32 \\
46 \\
22 \\
16 \\
27 \\
36 \\
63 \\
60\end{array}$ & $\begin{array}{l}\mathbf{M} \\
\mathbf{M} \\
\mathbf{M} \\
\mathbf{M} \\
\mathbf{F} \\
\mathbf{M} \\
\mathbf{F} \\
\mathbf{M} \\
\mathbf{M} \\
\mathbf{M} \\
\mathbf{M}\end{array}$ & $\begin{array}{c}\text { AS } \\
\text { AS-AI } \\
\text { AS } \\
\text { AS-AI } \\
\text { AS-AI } \\
\text { AS } \\
\text { AS } \\
\text { sub-AS } \\
\text { AS } \\
\text { AS and coarct. } \\
\text { AS } \\
\text { AS } \\
\text { Aortic }\end{array}$ & $\begin{array}{l}\text { Yes } \\
\text { No } \\
\text { Yes } \\
\text { No } \\
\text { Yes } \\
\text { ", } \\
\text {," } \\
\text { ", } \\
\text {," } \\
\text { No }\end{array}$ & $\begin{array}{l}\text { Poor } \\
\text { Damped } \\
\text { Good } \\
\text { Damped } \\
\text { Fair } \\
\text { Good } \\
\text { Fair } \\
\text { Good } \\
\quad, \\
\text { ", }\end{array}$ \\
\hline $\begin{array}{l}14 \\
15 \\
16 \\
17 \\
18 \\
19 \\
20 \\
21 \\
22\end{array}$ & $\begin{array}{l}\text { J.G. } \\
\text { *H.M. } \\
\text { P.D. } \\
\text { P.B. } \\
\text { T.H. } \\
\text { R.B. } \\
\text { R.B. } \\
\text { W.D. } \\
\text { J.C. }\end{array}$ & $\begin{array}{l}18 \\
47 \\
21 \\
6 \\
46 \\
16 \\
52 \\
31 \\
50\end{array}$ & $\begin{array}{l}\mathbf{M} \\
\mathbf{M} \\
\mathbf{F} \\
\mathbf{M} \\
\mathbf{M} \\
\mathbf{M} \\
\mathbf{F} \\
\mathbf{M} \\
\mathbf{M}\end{array}$ & $\begin{array}{c}\text { AI + VSD } \\
\text { AS-AI } \\
\text { AS } \\
\text { AS and coarct. } \\
\text { AS } \\
\text { AS } \\
\text { AS-AI } \\
\text { AS-AI } \\
\text { sub-AS and }\end{array}$ & 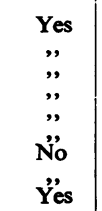 & $\begin{array}{l}\text { Good } \\
\text { ", } \\
", \\
\text { ", } \\
\text { Good }\end{array}$ \\
\hline $\begin{array}{l}23 \\
24\end{array}$ & $\begin{array}{l}\text { S.W. } \\
\text { E.G. }\end{array}$ & $\begin{array}{l}49 \\
61\end{array}$ & $\begin{array}{l}\mathbf{M} \\
\mathbf{F}\end{array}$ & Hyper & ", & ", \\
\hline $\begin{array}{l}25 \\
26\end{array}$ & $\begin{array}{l}\text { J.R. } \\
\text { M.W. }\end{array}$ & $\begin{array}{l}24 \\
11\end{array}$ & $\begin{array}{l}\mathbf{F} \\
\mathbf{M}\end{array}$ & $\begin{array}{l}\text { isch. } \\
\text { AS } \\
\text { Severe AS } \\
\text { and sub-AS }\end{array}$ & \multirow{2}{*}{\multicolumn{2}{|c|}{$\begin{array}{l}\text { Subvalvar chamber } \\
\text { entered, but not } \\
\text { aorta } \\
\text { Yes | Good } \\
\text { No. LV pressure } \\
450 \mathrm{~mm} \text {. Hg and } \\
\text { tiny occentric ori- } \\
\text { fice }\end{array}$}} \\
\hline $\begin{array}{l}27 \\
28 \\
29\end{array}$ & $\begin{array}{l}\text { M.H. } \\
\text { V.B. } \\
\text { E.D. }\end{array}$ & $\begin{array}{l}39 \\
56 \\
33\end{array}$ & $\begin{array}{l}\mathbf{F} \\
\mathbf{F} \\
\mathbf{M}\end{array}$ & $\begin{array}{l}\text { Coarct. } \\
\text { AS } \\
\text { AS }\end{array}$ & & \\
\hline $\begin{array}{l}30 \\
31 \\
32 \\
33 \\
34\end{array}$ & $\begin{array}{l}\text { R.W. } \\
\text { J.B. } \\
\text { S.D. } \\
\text { J.Br. } \\
\text { R.T. }\end{array}$ & $\begin{array}{r}17 \\
5 \\
54 \\
24 \\
57\end{array}$ & $\begin{array}{l}\mathbf{M} \\
\mathbf{M} \\
\mathbf{M} \\
\mathbf{F} \\
\mathbf{M}\end{array}$ & $\begin{array}{c}\text { sub-AS } \\
\text { AS } \\
\text { sub-AS } \\
\text { AS-ai } \\
\text { AS }\end{array}$ & $\begin{array}{l}\text { Yes } \\
\ddot{\prime} \\
\text { No. Sn }\end{array}$ & $\begin{array}{l}\text { Good } \\
\text { ", } \\
\text { nall" eccen- }\end{array}$ \\
\hline $\begin{array}{l}35 \\
36\end{array}$ & R.B. & $\begin{array}{l}47 \\
25\end{array}$ & $\mathbf{M}$ & $\begin{array}{l}\text { AS-ai } \\
\mathbf{A S}-\mathbf{A I}\end{array}$ & \multicolumn{2}{|c|}{$\begin{array}{l}\text { No. Small'eccen- } \\
\text { tric orifice } \\
\text { Yes Good }\end{array}$} \\
\hline
\end{tabular}

* L.A. also entered and good withdrawal trace across mitral valve. A.S. $=$ aortic valve stenosis; A.I. = aortic valve incompetence; sub-AS = subaortic stenosis; VSD = ventricular septal defect.

It would be fortunate if the orifice could be entered in these cases. Reference to Table I shows that in four of the remaining five failures there was a significant degree of aortic regurgitation. This is not thought to be of importance in the failure, which can be explained more readily on other grounds. All these four cases occurred at an early stage in the operators' experience.

Although there were difficulties in the first cases, the pressure tracings obtained in the last 30 cases have been uniformly excellent. The ease of entering the aorta is in contrast to our experience with left atrial puncture (Björk, Blakemore, and Malmström, 1954) where we have frequently failed and prolonged manipulations of the catheter tip within the left ventricle have given rise to severe arrhythmia. Figs. 2-7 show the minimal disturbance to rhythm using the present method. Only in Fig. $\overrightarrow{\bar{B}}$ is there an ectopic beat. On this record the electro음 cardiogram had failed.

In a normal aortic valve there is no systolic gradient and there is a clean change from aortio to left ventricular pulse (Fig. 2). In aortic valve् stenosis there is a single systolic gradient and thetransition from aortic to ventricular pulse also occurs abruptly, without intermediate pulse formई (Fig. 3). Artefacts may occur when the tip of the catheter is just at the valve. It is important to have a simultaneously recorded electrocardiogram ${ }_{\downarrow}$ to ensure that these are not due to arrhythmia. A false appearance of subvalvar stenosis may be prose duced by too slow a withdrawal, the catheter tipo being flung into the aorta in systole and drawn into the ventricle in diastole. The resultant trace resembles that from an infundibular chamber With experience a steady, slow rate of withdrawal can be achieved and any questionable results can be checked by repeating the withdrawal. The pressure pulse from a brachial artery is recorded at the same time. In the event of failure to enter the aorta, the systolic gradient across the aortic valve can still be measured.

It is known that a diaphragmatic type of stenosis, immediately below the valve, may appea valvar on a withdrawal trace. Brock and Fleming (1956) report this as occurring at operation. Ing this series we have had one such case in which ouọ. investigation indicated a stenosis at valve leve only. This was confirmed by a withdrawal $a$ operation, but the valve was normal and the्र stenosis lay so immediately under the valve as to make it likely that the valve cusps were in contact. with the stenosis in diastole.

In the present series five cases of subvalva负 obstruction have been identified. None of these has yet come to operative confirmation. Two examples from this group are given later.

\section{Illustrative Cases}

CASE 18.-T. H., a man aged 46 , was found to have a heart murmur at the age of 10 years. Nine months before admission he developed paroxysmal nocturnat dyspnoea and angina. He had an anacrotic pulse buf a blood pressure of $160 / 120 \mathrm{~mm}$. Hg. There was clinical, electrocardiographic, and radiological evidence ${ }^{+}$ of gross left ventricular hypertrophy. There was a marked aortic systolic murmur and thrill and the second sound was single. There was gross calcificas tion in the region of the aortic valve, but the level of the blood pressure was disturbing. A withdrawaf record (Fig. 3) from the aorta to the left ventricle showed a single pressure change and the valvaf stenosis was confirmed at operation. 


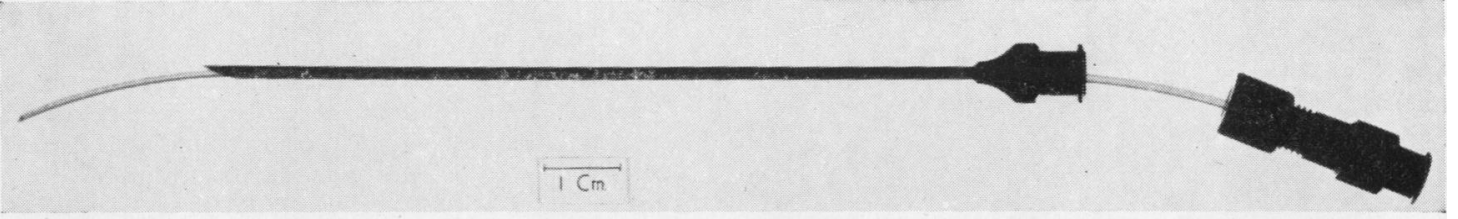

Fig. 1.-The needle, catheter (cut short for illustration), and adaptor assembly used for left ventricular puncture and catheterization of the aorta.

$\mathrm{mm} \cdot \mathrm{Hg}$

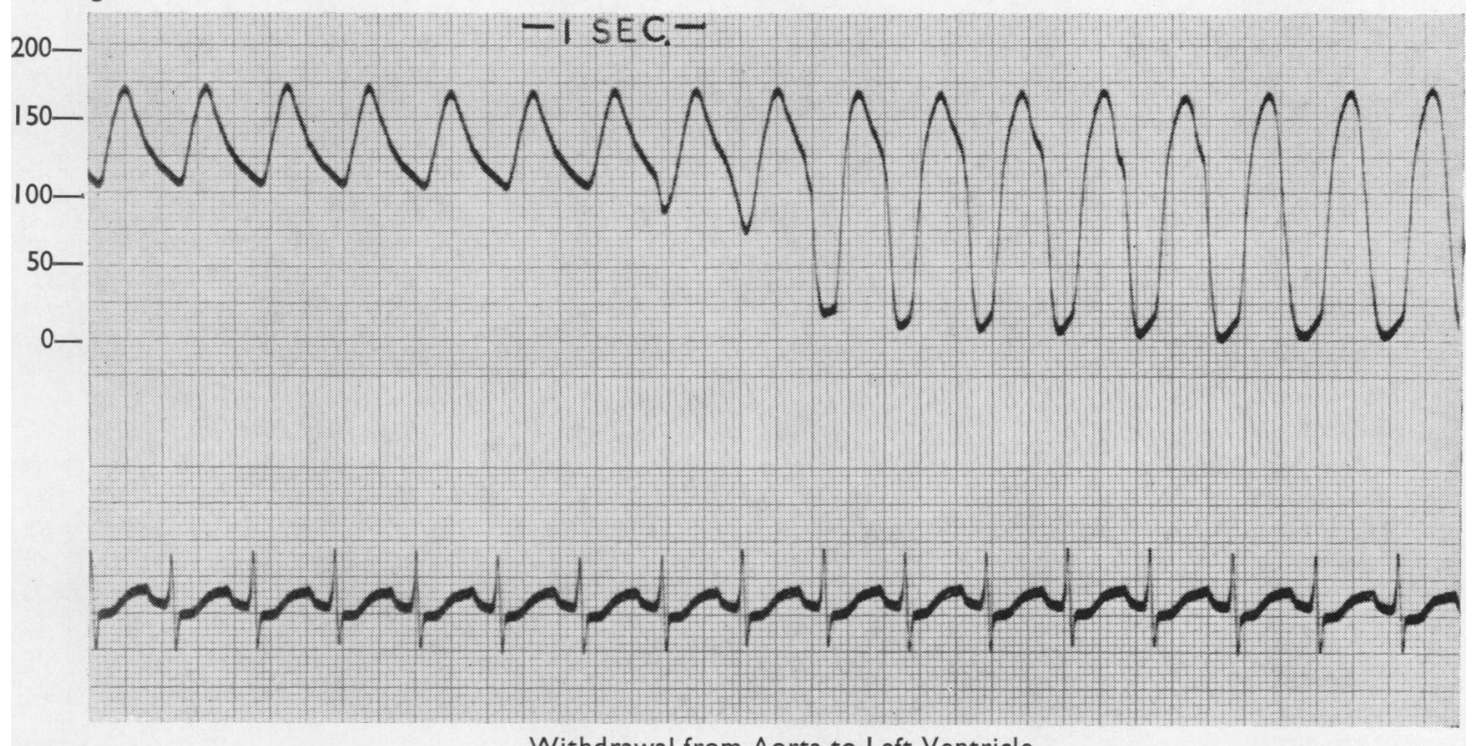

Withdrawal from Aorta to Left Ventricle

Fig. 2.-Example of a withdrawal record across a normal aortic valve. Case 27 with coarctation of the aorta and a falling blood pressure.

$\mathrm{mm} \cdot \mathrm{Hg}$

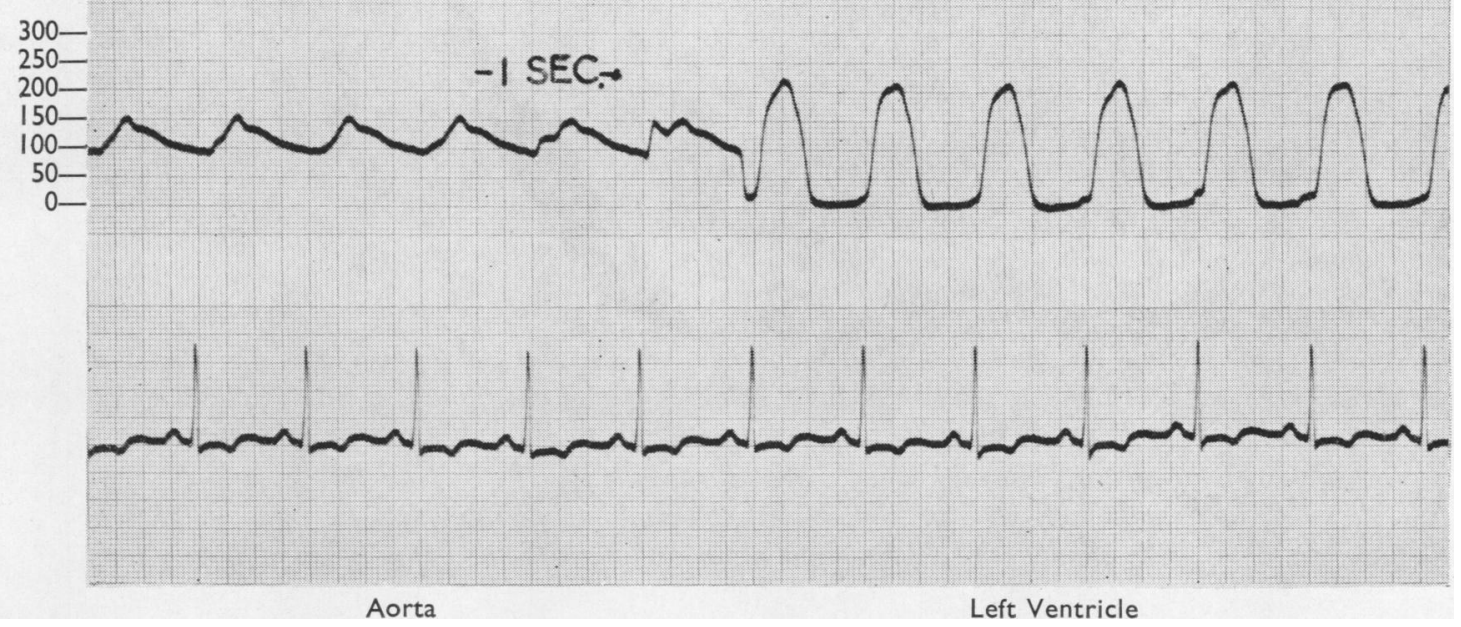

FIG. 3.-Example of a withdrawal record in Case 18 with systemic hypertension and moderate aortic stenosis. There is a systolic gradient of $70 \mathrm{~mm} . \mathrm{Hg}$ at the aortic valve. 


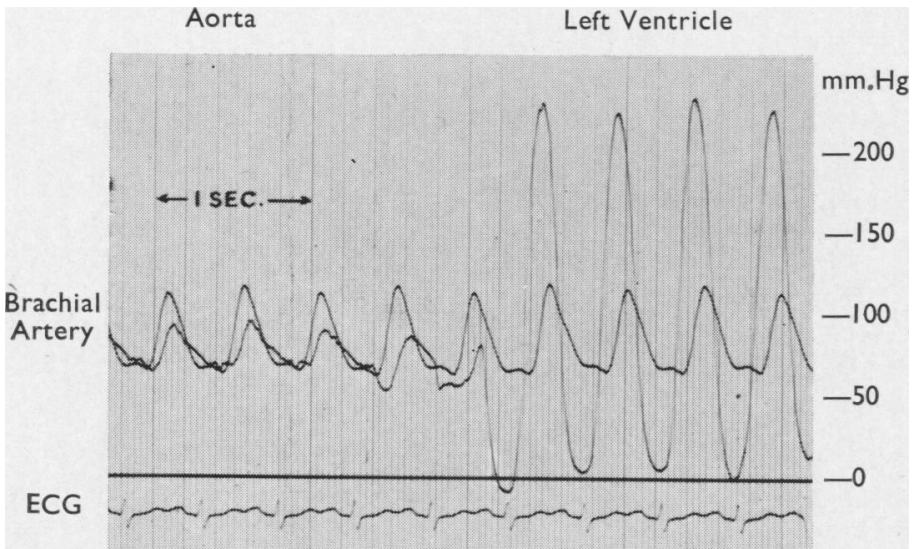

Fig. 4.-Withdrawal record of Case 35 from aorta to left ventricle, with simultaneous brachial artery record, in a typical case of severe aortic stenosis. The systolic gradient is $100 \mathrm{~mm}$. Hg and there is a slight pulsus alternans. The difference in pulse form between the aorta and the brachial artery is more marked than is usual in aortic stenosis.

CASE 35.- G. E. was a man of 46 with a six months' history of angina pectoris and progressive breathlessness on exertion. There was a loud aortic systolic murmur and thrill conducted into the carotids, a delayed aortic second sound, and a slight aortic diastolic murmur. Blood pressure was $130 / 60 \mathrm{~mm}$. $\mathrm{Hg}$. Electrocardiogram indicated extreme left ventricular hypertrophy, and aortic valve calcium was clearly seen on fluoroscopy. Left ventricular puncture showed a systolic gradient of $100 \mathrm{~mm}$. $\mathrm{Hg}$ across the aortic valve, and a withdrawal record showed an abrupt change from aorta to left ventricle typical of aortic valve stenosis (Fig. 4), which was verified at operation.
CAse 33.-J. Br. was a 24-year $\overrightarrow{\overline{\vec{F}}}$ old woman with angina pectoriso and cardiac failure. There was के loud aortic systolic murmur with $\overline{\bar{s}}$. a single second sound and a sof aortic diastolic murmur. Bloode pressure was $130 / 90 \mathrm{~mm}$. Hg. Elec-w trocardiogram indicated left ventricular hypertrophy. Slight aortic? valve calcification was shown by $\vec{\omega}$ tomography. Left ventricularo puncture with catheterization of the aorta showed a systolic pres $\bar{x}$ sure gradient of $130 \mathrm{~mm}$. $\mathrm{Hg}$, and $\vec{\omega}$ a withdrawal record was typical of aortic valve stenosis (Fig. 5) sub sequently verified at operation.

CASE 30.-R. W. was a 17-year= old boy whose heart murmur wase discovered at the age of 5 years and who had a reduced exercise ${ }^{\mathbb{D}}$ tolerance because of fatigue ande breathlessness. The pulse was sharp and full, there was a marked left ventricular heave and a rough systolic murmur over the whole praecordium. Blood pressure was $130 / 60 \mathrm{~mm}$. $\mathrm{Hg}$ Electrocardiogram indicated marked left ventricula hypertrophy. Fluoroscopy showed marked enlarge ment of the left ventricle and no valve calcium. Lef ventricular puncture with catheterization of the aorta showed a systolic gradient of $50 \mathrm{~mm}$. $\mathrm{Hg}$, and theo withdrawal record was characteristic of aortic sub 3 valvar stenosis (Fig. 6). Operation was deferred.

CASE 32.-S. D. was a man of 54 years with angina pectoris, syncope, and progressive breathlessness onf exertion. There was a loud aortic systolic murmur and a single second sound. Electrocardiogram indi

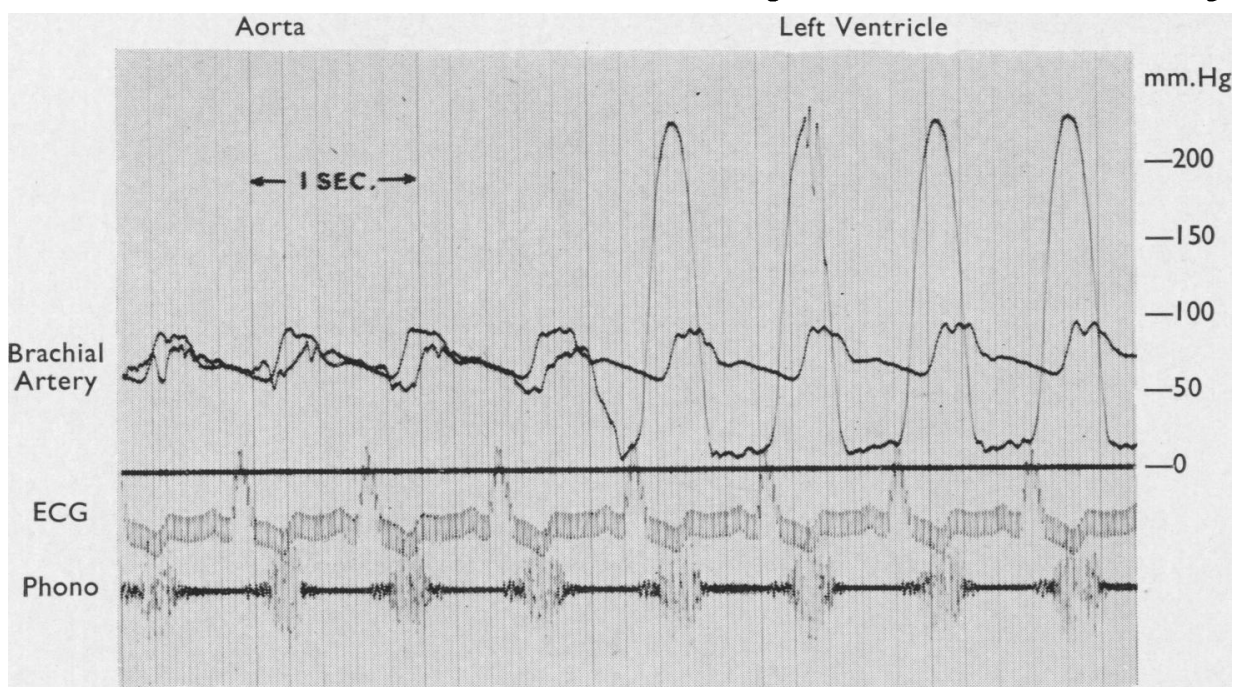

Fig. 5.-Withdrawal record of Case 33 from aorta to left ventricle, with simultaneous brachial artery record, in a case of severe aorti valve stenosis (systolic gradient $130 \mathrm{~mm} . \mathrm{Hg}$ ) of presumed congenital origin. 
cated considerable left ventricular hypertrophy and a tria 1 fibrillation. Radiology showed marked left ventricular enlargement, bu t no calcification of the aortic valve could be demonstrated. Left ventricular puncture showed a systolic gradient of 100 $\mathrm{mm}$. $\mathrm{Hg}$, but a withdrawal record showed that the obstruction was subvalvar (Fig. 7). This condition was considered inoperable.

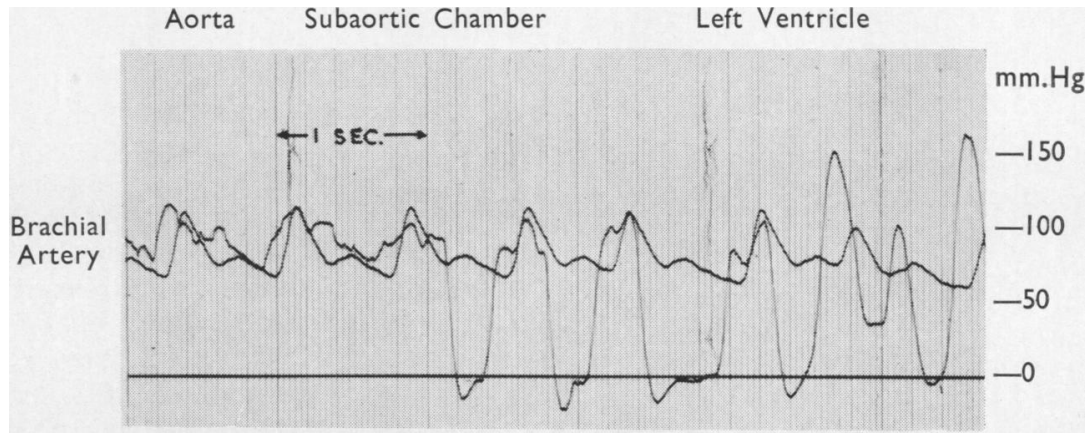

Fig. 6.-Withdrawal record of Case 30 from aorta to left ventricle, with simultaneous brachial artery record, showing the gradient $(50 \mathrm{~mm}$. $\mathrm{Hg})$ to be localized to a subvalvar site in the left ventricle rather than at the valve.

\section{COMPLICATIONS}

There have been two deaths in this series. These are the only deaths attributable to left ventricular puncture in a total of 115 cases investigated at these two hospitals.

CASE 24.-The first patient was a woman of 61 years with a history of hypertension. She was in intractable congestive heart failure, had a low cardiac output (1.5 $1 . / \mathrm{min}$.), extreme pulmonary vascular resistance (28 units), and features of aortic stenosis. The procedure was accomplished easily and there was no aortic gradient. Death occurred within four hours from cardiac tamponade and blood loss, in spite of aspiration and transfusion. Necropsy showed that the left ventricular puncture needle had traversed the scar of a small, healed apical myocardial infarct only $3 \mathrm{~mm}$. in thickness. It was from this site that the bleeding had occurred. There was severe coronary atherosclerosis.

CASE 34.-The second case was a man aged 57 years who had suffered for several years from angina pectoris, syncope, effort and nocturnal dyspnoea, and congestive cardiac failure. He had the signs of calcific aortic stenosis. Left ventricular puncture was easily accomplished, but the catheter could not be introduced into the aorta. There was a fall in blood pressure without other clinical signs of tamponade, but cardiac arrest occurred suddenly 20 minutes later. Thoracotomy revealed a substantial haemopericardium. Resuscitation efforts failed and necropsy revealed extreme aortic valve stenosis with a tiny, eccentrically placed orifice.

From this experience it is felt that patients with any possibility of ischaemic heart disease or myocardiopathy should not be submitted to left ventricular puncture. It will not always be easy to avoid such cases, but a preliminary arterial pulse tracing may be helpful in deciding whether aortic stenosis must still be seriously considered (Wood, 1958) and further investigation necessary.

The classical post-pericardiotomy syndrome (Papp and Zion, 1956) has occurred in two cases. This has been similar in all respects to that occurring after cardiac operations and, when treatment

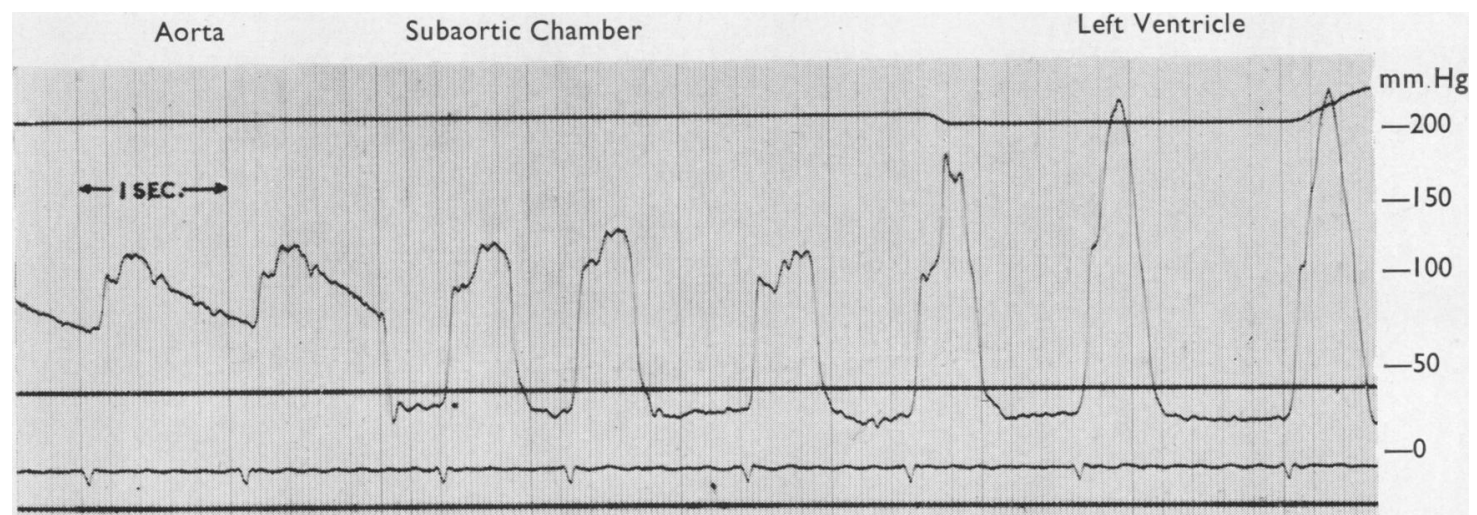

Fig. 7.-Withdrawal record of Case 32 from aorta to left ventricle, showing a subvalvar site of the pressure gradient (100 mm. $\mathrm{Hg}$ ): The same appearance was obtained on repeated withdrawal tracings. Operation has not been undertaken. 
was necessary, there has been a good response to prednisone. The recognition of this complication is important as, in these two cases, the onset was sudden and severe, some days after the puncture. There was considerable pain with transient collapse, and myocardial infarction could have been diagnosed. The early appearance of a pericardial rub and the subsequent course made the true diagnosis evident.

A small number of patients have suffered from severe pericardial pain at the time of the puncture. This has been treated with intravenous pethidine and has not been accompanied by other signs.

One patient, aged 5 years, had chest pain of sudden onset four days after puncture (Case 31 ). The neck veins were distended and the pulse was paradoxical. Cardiac tamponade was diagnosed but subsided uneventfully without treatment.

\section{Discussion}

The simplicity of the method and the excellent quality of the traces obtained are encouraging. However, the two deaths and the small number of other complications have been confined to the present series. As experience in the surgery of aortic stenosis (Brock, 1957a) has extended, more and more seriously ill patients have come to these hospitals for assessment, and the risk of any procedure, however small, in such cases is considerable. Nevertheless it cannot be denied that the use of a larger and more rigid needle and the slightly longer time necessary for the manipulation may make the procedure a more dangerous one in poor-risk cases. It is therefore suggested that its use be confined to patients in whom congenital subaortic stenosis is suspected, those without calcium in the valve, and those with a history of systemic hypertension.

\section{Summary AND CONClusions}

Catheterization of the aorta with a fine plastic catheter is described as an addition to the technique of percutaneous left ventricular puncture in $\mathbb{D}$ the diagnosis and assessment of aortic stenosis. The procedure has been successful in 28 of the first 36 attempts. Aortic pressure tracings and. excellent withdrawal records across the valve have $\overrightarrow{\vec{\omega}}$ been regularly obtained. Five cases of subvalvar $\stackrel{\circ}{\omega}$ stenosis have been identified and one missed by $\overrightarrow{\vec{x}}$ this method. Two deaths have occurred, the only deaths in a total of 115 left ventricular punctures. It is suggested that this method is valuable, but that in cases with a poor myocardium there is an increased risk of haemorrhage. Its use should therefore be confined to cases where it is par- $\vec{c}$ ticularly indicated, and if the gradient alone is to be measured the technique of left ventricular and $\overline{\mathrm{D}}$ brachial artery puncture will give the information.

We wish to thank Sir Russell Brock for much help and encouragement; Dr. Paul Wood, Dr. R. V. O Gibson, Dr. C. Baker, and Sir Russell Brock under whose care patients were investigated. Mr. M. Paneth and Dr. A. M. Johnson have assisted in these investigations. The illustrations are the results of the work $\mathbb{D}$ of the cardiological technicians and the photographic departments of both hospitals.

\section{REFERENCES}

Björk, V. O., Blakemore, W. S., and Malmström, G. (1954). Amer.

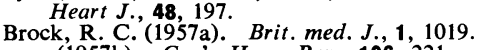

(1957b). Guy's Hosp. Rep., 106, 221

and Fleming, P. R. (1956). Ibid., 105, 391.

- Milstein, B. B., and Ross, D. N. (1956). Thorax, 11, 163.

Fleming, P. R., and Gibson, R. V. (1957). Ibid., 12, 37

Papp, C., and Żion, M. M. (1956). Brit. Heart J., 18, 153.

Wood, P. (1958). Amer. J. Cardiol., 1, 553.

Wright, J. L., Toscano-Barboza, E., and Brandenburg, R. O. (1956). Proc. Mayo Clin., 31, 120.

\section{ADDENDUM}

Since this paper was submitted for publication a $>$ further 43 patients at these two hospitals have had left ventricular puncture without complications. N Of these, 23 also had the aorta catheterized. 